\title{
DISCURSOS SOBRE GÊNERO, DIVERSIDADE SEXUAL E HOMOFOBIA NO CONTEXTO ESCOLAR
}

\begin{abstract}
Rubenilson Pereira de Araújo é professor efetivo da rede pública estadual de ensino do Estado do Tocantins e do Instituto Tocantinense Presidente Antônio Carlos (ITPAC/Campus de Porto Nacional). Atualmente, desenvolve pesquisa sobre as práticas discursivas de subjetivação no ambiente escolar no Mestrado em Letras: Ensino de Língua e Literatura da Universidade Federal do Tocantins.

E-mail: rubenilsonpereira@gmail.com
\end{abstract}

Flávio Pereira Camargo é professor Adjunto da Universidade Federal do Tocantins, atuando na graduação em Letras e no curso de Pós-Graduação em Letras: Mestrado em Ensino de Língua e Literatura. Desenvolve e orienta pesquisas sobre questões relacionadas à narrativa brasileira contemporânea, aos estudos de gênero e sexualidades e suas interfaces com a educação.

E-mail: camargolitera@uft.edu.br

Resumo: Neste artigo, propomos uma discussão acerca dos discursos sobre gênero, diversidade sexual e homofobia no contexto escolar. Nossas análises são sustentadas pelos princípios teóricos e críticos advindos dos Estudos Culturais, particularmente aqueles referentes aos estudos de gênero e suas interfaces com o currículo.

\begin{abstract}
In this paper, we propose a discussion of the discourses on gender, sexual diversity and homophobia in the school context. Our analysis is supported by the principles arising from the theoretical and critical cultural studies, particularly those relating to gender studies and their relations with the curriculum.
\end{abstract}

Até outro dia, não sabíamos como fazer para introduzir as aflições e os anseios de pessoas que se atrevem a dizer o nome de um amor, a pronunciar no seu corpo, na sua voz, na sua presença, na sua literatura, na sua aula, no seu trabalho, o desejo de construir para si o direito de decidir como viver, como quer buscar o seu prazer, como quer o seu corpo e com quem quer dividir o seu desejo. Hoje sabemos mais, porém ainda é pouco. Isso nos exige coragem e criatividade!

Prado e Machado, 2008, p. 122.

\section{1) Delimitando o campo da pesquisa}

Atualmente o espaço escolar ainda se mostra hostil e resistente à diversidade, entre elas, a sexual. Na verdade, "sempre houve, por parte da escola, grande resistência à incorporação das transformações por que passam o conhecimento e os meios de transmissão e difusão" (D'Ambrósio, 1999, p. 72). Sabemos que há documentos legais 
que explicitam a laicidade do país e os direitos básicos da dignidade e da integridade do ser humano, o que nos leva a compreender que essa hostilidade infringe os direitos humanos. Daí a necessidade de que a instituição escolar e demais segmentos sociais tem em se sensibilizarem de que se trata de uma violação de uma série de direitos básicos, reconhecidos tanto pelos direitos universais do homem, como pela constituição brasileira. Afinal, "[h]omens e mulheres da mídia, da educação, da cultura, da saúde, da justiça, dos movimentos sociais, entre outras áreas, vêm apontando os dedos para a questão, denunciando ou finalmente admitindo: a homofobia é um grave problema social" (Junqueira, 2007, p. 02).

Em nossa pesquisa, optamos por um estudo de caso sobre as práticas discursivas de subjetivação no ambiente escolar. Como subsídio para a coleta dos dados, utilizamos a metodologia com base em entrevistas semi-estruturadas com alunas e alunos, professoras e professores, diretora e coordenação pedagógica da escola-campo, uma instituição pública estadual, situada em uma região periférica no município de Porto Nacional, no Estado do Tocantins.

No decorrer de nossa coleta de dados, entrevistamos, por um lado, a diretora geral da Unidade Escolar, a Orientadora Educacional, e uma amostragem de 05 (cinco) professores regentes de turma do $2^{\circ}$ ano do Ensino Fundamental até o Ensino Médio. Por outro lado, com o objetivo de analisar os discursos e saberes que são produzidos sobre gênero, diversidade sexual e homofobia no ambiente escolar, também entrevistamos uma amostragem de 10 (dez) alunos regularmente matriculados nas séries finais do Ensino Fundamental e Médio da escola-campo, incluindo-se aí o aluno I e a aluna II, membros do Grêmio Estudantil, e os alunos egressos VII, VIII, IX e X, homossexuais assumidos. Destes últimos, 01 (um) concluiu o Ensino Médio e não prosseguiu em seus estudos, outro progrediu e se encontra no nível superior e 02 (dois) evadiram da escola antes de concluírem a Educação Básica.

Neste artigo, em um primeiro momento, propomos uma reflexão de cunho teórico e crítico sobre o tripé gênero, sexualidade e currículo, para, em seguida, analisar alguns recortes das entrevistas realizadas com as alunas e os alunos (homossexuais e heterossexuais) da escola-campo. A partir dos dados obtidos, tecemos uma discussão acerca dos discursos sobre gênero, diversidade sexual e homofobia no contexto escolar e as suas implicações sociais no cotidiano de alunas e alunos homossexuais.

\section{2) Gênero, sexualidade e currículo: um diálogo possível e necessário}

Na contemporaneidade, a escola pública brasileira está vencendo o desafio de ofertar o acesso a uma educação para todos por meio de políticas públicas educacionais que possibilitam, "pela primeira vez na história brasileira, vagas para todas as crianças 
em idade de cursar as séries do Ensino Fundamental" (Seffner, 2009, p. 126). Entretanto, é importante perceber que "a diferença entre acesso e inclusão é enorme", pois entre as estratégias de inclusão torna-se necessário programar "ações de acolhida e verdadeiro interesse em conhecer quem são os novos públicos de alunos que passaram a ter acesso à escola" (Seffner, 2009, p. 134).

O que verificamos é o ingresso de um público bastante heterogêneo na escola, justamente por se tratar de crianças e de jovens pertencentes a classes socioeconomicamente desfavorecidas, geralmente excluídas dos benefícios que a educação formal pode promover e, principalmente, tolhidas de exercerem plenamente sua cidadania. Esse fato gera um forte desafio em todas as estruturas escolares: "Em particular, esse impacto é percebido quando da definição de temas e conteúdos a serem ensinados, de regras de conduta e convívio escolar a serem obedecidas [...]. [de tal modo que] [...] a escola pública brasileira vive hoje o desafio de aceitar os "diferentes"" (Seffner, 2009, p. 126-128).

É justamente a possibilidade de aceitar o outro, o "diferente", um dos dilemas de nosso sistema educacional na atualidade. Para Tomaz Tadeu da Silva, "a diferença não é uma característica natural: ela é discursivamente produzida" (2000, p. 89), ou seja, ela é construída. É justamente por isso que é por meio e através dos discursos que produzimos e realimentamos certas diferenças de identidades de gênero, sexuais, e étnico-raciais, entre outras, que podem gerar conflitos e desestabilizar certos paradigmas tradicionais cristalizados, pois "são os próprios valores da civilização ocidental [...] que estão em risco quando o estilo de vida dos homossexuais, por exemplo, se torna matéria curricular" (Silva, 2000, p. 92).

Em relação aos estudos de gênero, devemos muito aos estudos feministas que, durante muitos anos, lutou bravamente para conseguir espaço e reconhecimento junto à academia e à sociedade: "a crescente visibilidade do movimento e da teorização feminista [...] forçou as perspectivas críticas da educação a concederem importância crescente ao papel do gênero na produção da desigualdade" (Silva, 2000, p. 94). De acordo com Louro (2010), foi este movimento que deu voz e espaço àquelas que eram silenciosas e silenciadas, focalizando áreas, temas e problemas que não existiam no espaço acadêmico, falando do cotidiano, da família, da sexualidade, do doméstico, dos sentimentos femininos. Enfim, uma tentativa e uma possibilidade de apreensão e compreensão de um universo feminino que antes havia sido relegado ao segundo plano ou visto somente pela perspectiva masculina, marcada principalmente por um paradigma patriarcal e heteronormativo.

A inclusão de discussões sobre questões de gênero, sexualidade e identidade no ambiente escolar pode possibilitar às nossas alunas e alunos uma sensibilização sobre a necessidade em respeitarmos o outro, sobretudo no que diz respeito à sexualidade, algo que é inerente ao ser humano. Para Louro (2007), a sexualidade não é uma questão apenas pessoal, mas social e política e nos remete ao que, de fato, somos enquanto ser 
subjetivo e social. Afinal, "o sexo sempre foi o núcleo onde se aloja, juntamente com o devir de nossa espécie, nossa "verdade" de sujeito humano" e é no "seu sexo [que] está o segredo de sua verdade" (Foucault, 1993, p. 127; 152).

Ademais, também gostaríamos de ressaltar que

[a sexualidade] nos remete a nossa origem (quem somos, de onde viemos, como fomos concebidos) e, consequentemente, a origem do próprio conhecimento, da curiosidade e da disposição para aprender. Sexualidade tem a ver com identidade e com as infinitas maneiras de ser homem ou de ser mulher na sociedade e na cultura e com o caminho pessoal da construção de cada um [...]. Uma questão tão importante como é da sexualidade não poderia deixar de ser trabalhada na educação e se constitui política pública (Egypto, 2009, p. 341).

De acordo com Antônio Carlos Egypto (2009), um dos colaboradores da equipe de elaboração dos Parâmetros Curriculares Nacionais do MEC, referente aos temas transversais de Orientação Sexual, trata-se de "uma discussão franca e aberta da sexualidade, tão absolutamente indispensável na contemporaneidade" no processo pedagógico de forma sistematizada. Para o autor, o tripé constituído pela intencionalidade, planejamento e sistematização é basilar no contexto escolar para uma "reflexão sobre a sexualidade, problematizando os temas polêmicos favorecendo ampla liberdade de expressão em ambiente acolhedor que visa promover o bem-estar sexual e vínculos mais significativos, ampliando a cidadania" (Egypto, 2009, p. 342-343). Percebemos que a proposta dos PCN's é interessante e extremamente significativa para os estudos de gênero ao propor ações em uma perspectiva transdisciplinar, um trabalho contínuo que "deve começar na Educação Infantil e se estender até o final do Ensino Médio" (Egypto, 2009, p. 342-343), afinal "a sexualidade é um elemento determinante na constituição dos sujeitos, tão necessário quanto o ar que respiramos" (Prado; Machado, 2008, p. 15). No entanto, gostaríamos de ressaltar que o próprio Antônio Carlos Egypto considera como "temas polêmicos" o que diz respeito a uma discussão sobre gênero, identidade e sexualidade.

Esta ressalva, por parte do autor, nos remete ao percurso da história da sexualidade traçado por Foucault em seus estudos, nos quais verifica que, na

Antiguidade grega e romana, na qual a sexualidade era livre, se expressava sem dificuldades e efetivamente se desenvolvia, sustentava em todo caso um discurso na forma de arte erótica. Depois o cristianismo interveio, o cristianismo teria, pela primeira vez na história do Ocidente, colocando uma grande interdição à sexualidade, que teria dito não ao prazer e por aí mesmo ao sexo. Esse não, essa proibição teria levado a um silêncio sobre a sexualidade - baseado essencialmente em proibições morais (2006, p. 62-63). 
Trata-se, pois, de uma "interdição à sexualidade" e, consequentemente, aos seus discursos que têm como motor certos valores morais, sociais, culturais e históricos praticamente impostos por um fundamentalismo religioso. Neste sentido, a temática de gênero e sexualidade é considerada polêmica justamente porque em nossa sociedade ainda prevalecem valores socioculturais e morais que preconizam única e exclusivamente a união entre pessoas de sexo oposto, preferencialmente no matrimônio, discriminando aqueles que não se encaixam em determinadas regras morais e sociais convencionadas por uma cultura marcadamente heteronormativa, patriarcal e falocêntrica.

O que há, de fato, na sociedade, é uma produção de discursos e saberes sobre a sexualidade que "se constitui a partir de múltiplos discursos sobre o sexo: discursos que regulam, que normalizam, que instauram saberes, que produzem 'verdades"' (Louro, 2010, p. 26). E estas "verdades" produzidas social e culturalmente podem mudar, pois elas são cambiantes, relativas, transitórias e efêmeras.

Insistimos que questões diversas relacionadas ao gênero, à sexualidade e à identidade são basilares na formação de nossos alunos, pois "a sexualidade está na escola porque ela faz parte dos sujeitos, ela não é algo que possa ser desligado ou algo do qual alguém possa se "despir" (Louro, 2010, p. 81) e "o gênero é uma dimensão central na vida das pessoas e está incessantemente sendo construído e reconstruído nas relações sociais e interações com outros indivíduos" (Borges; Meyer, 2008, p. 62). Daí a necessidade de se discutir, problematizar e questionar os discursos sobre as sexualidades e os gêneros na escola "porque esse é um campo político, ou seja, porque na instituição das diferenças estão implicadas relações de poder” (Louro, 2010, p. 84, grifos da autora).

Outra estudiosa que endossa esta perspectiva de inserção de um debate público e em diversas esferas da sociedade acerca das questões de gênero, sexualidade e identidade é Maria Luiza Heilborn, para quem a

[sexualidade] tornou-se nas últimas décadas um assunto cada vez mais importante no debate público. Ela se transformou, por intermédio, de um longo processo de mudanças históricas uma área da vida à qual se atribui muito significado, exprimindo um lugar de realização, de definição de identidade pessoal. Disseminou-se a ideia de que a sexualidade deriva de um impulso vital, presente em toda a humanidade, que brota do íntimo e do profundamente subjetivo de cada pessoa (2010, p.01).

Luiz Paulo da Moita Lopes, em relação a esta questão, afirma:

[igualmente] quem iria pensar que as novelas na TV, assistidas pelas famílias na hora do jantar, mostrariam casais constituídos por dois homens ou por duas mulheres ou até mesmo por dois homens e uma mulher [...]. De repente, o amor entre pessoas do mesmo 
sexo deixa a privacidade das quatro paredes, ocupa a sala de jantar e pode ser pensado como uma forma de exercício do discurso amoroso como qualquer outro (2008, p. 13).

Entretanto, o que verificarmos é certo distanciamento expressivo entre a teoria presente nos documentos oficiais e a prática pedagógica em nossas escolas. Aliás, esta ausência de discussão já foi apontada por Foucault em seu percurso sobre a história da sexualidade ao constatar que "[o] sexo foi aquilo que, nas sociedades cristãs, era preciso examinar, vigiar, confessar, transformar em discurso" (1993, p. 230) e, consequentemente, tais construtos socioculturais fizeram a escola "funcionar como uma máquina de ensinar, mas também de vigiar, de hierarquizar, de recompensar" (2009, p. 142), de modo que houve uma produção de discursos sobre o sexo e a sexualidade humana, mas com o objetivo de vigiar, de punir, de levar os indivíduos a confessarem suas práticas sexuais não permitidas pela Igreja.

Dito isto, "a sexualidade foi o foco para onde se voltaram os olhares mais vigilantes. Para ela, e por ela, foram inventadas as mais diversas formas de controle e governo" (Louro, 2000, p. 38). O que podemos concluir destas considerações de Michel Foucault e de Guacira Lopes Louro é que sempre houve e ainda há em nossa sociedade mecanismos de poder que tentam controlar, vigiar, punir e governar os corpos e os desejos mais recônditos em uma tentativa vã de uniformização dos corpos e das identidades de gênero e sexuais.

A história oficial está permeada por "verdades" que são impostas como "absolutas" e "acabadas", contribuindo para a manutenção de alguns tabus acerca da sexualidade humana, mas cabe ao educador contemporâneo "duvidar dessas verdades e certezas sobre os corpos e a sexualidade, que vale a pena colocar em questão as formas como costumam ser pensados e as formas como identidades e práticas têm sido consagradas ou marginalizadas" (Louro, 2000, p. 86). Somente assim podemos tentar romper com uma neutralidade que é imposta por um paradigma científico tradicional e também por um currículo escolar que funciona como um mecanismo de poder e de discriminação, de modo que "ao fazer a história ou as histórias dessa pedagogia talvez nos tornemos mais capazes de desarranjá-la, reinventá-la e torná-la plural" (Louro, 2000, p. 86).

Paradoxalmente, pensando na necessidade de efetivar a inclusão escolar e educar para a diversidade, levando em consideração as diferenças de gênero e sexuais, percebemos que "a escola está intrinsicamente comprometida com a manutenção de uma sociedade dividida e que faz isso cotidianamente, com nossa participação ou omissão" (Louro, 2010, p. 85). Desta maneira, "a escola pública brasileira foi, e ainda é, largamente utilizada como instrumento de exclusão da cidadania", o que nos remete a uma contradição levando-nos a empreender esforços no sentido de tentar reverter esta situação e fazer com que a escola pública brasileira liberte-se "da sina de ser um local de exclusão" (Seffner, 2009, p. 128). 
Neste sentido, julgamos pertinente a relação entre as questões de gênero, identidade e sexualidade com a lógica do terceiro incluído, que propõe a inclusão de uma terceira possibilidade além do antagonismo estabelecido pelo paradigma tradicional. De acordo com Lúcia Facco, "a questão ultrapassa a discussão sobre sexualidade. Trata-se, antes, da discussão sobre as várias possibilidades de relacionamentos afetivo-amorosos" (2009, p. 50). A partir dessa lógica, torna-se possível repensar o binarismo de gênero (masculino-feminino), questionando-o enquanto construção social humana, altamente marcada pela presença heterossexual, incluindo a possibilidade de uma sexualidade alternativa, no caso, a(s) homossexualidade(s).

Esse rompimento de paradigmas e a desconstrução sociocultural de determinados valores é uma luta histórica, pois não se trata de algo relativamente simples, afinal "não é tarefa fácil, pois ela está marcada fortemente por este sinal" e "as proibições existem, são numerosas e fortes" (Seffner, 2009, p. 128). Estas regulações estão arraigadas em nosso meio social e "fazem parte de uma economia complexa em que existem ao lado de incitações, de manifestações, de valorizações. São sempre interditos que são enfatizados" (Foucault, 1993, p. 128), o que nos leva a empreender uma ampla discussão, densa, polêmica, mas principalmente necessária. Para tanto, devemos compreender o espaço escolar também como um ambiente político de defesa por igualdade de direitos, sobretudo o que se refere ao acesso à educação para todas e todos, uma vez que

[a]s instituições escolares são lugares de luta, e a pedagogia pode e tem que ser uma forma de luta político-cultural. As escolas como instituições de socialização têm como missão expandir as capacidades humanas, favorecer análises e processos de reflexão em comum da realidade, desenvolver nas alunas e alunos os procedimentos e destrezas imprescindíveis para sua atuação responsável, crítica, democrática e solidária na sociedade (Santomé, 2011, p. 175).

Apesar de haver discussões teóricas e críticas sobre a necessidade de revermos questões diversas relacionadas ao currículo e à formação de professores, ainda nos deparamos com uma escola presa ao paradigma tradicional que tende fortemente a desconsiderar e a ignorar as sexualidades plurais e alternativas, como é o caso da homossexualidade, o que contribui para reforçar "as visões hegemônicas a respeito da masculinidade e feminilidade. Os meninos são estimulados a serem agressivos, enquanto as meninas devem ser mais delicadas. Aceitam-se como "naturais", o que torna incompreensíveis aqueles que não corresponderem a tais expectativas" (Facco, 2009, p. 119), rompendo com aquela falsa neutralidade da escola em relação à sexualidade e às questões de gênero e de identidade, pois estas formas sucintas de controle do corpo, dos gestos, dos movimentos, das práticas corporais como um todo, são, na verdade, mecanismos de poder que advêm das práticas discursivas de 
subjetivação no ambiente escolar.

Além disso, ainda é possível observarmos certo apagamento e silenciamento por parte da escola em não considerar a diversidade sexual presente em nossa sociedade, contrariando o que preconiza o Plano Nacional de Educação em Direitos Humanos ao afirmar que "o processo formativo pressupõe o reconhecimento da pluralidade e alteridade, condições básicas da liberdade para o exercício da crítica, da criatividade, do debate de ideias e para o reconhecimento, respeito, promoção e valorização da diversidade" (Brasil, 2008, p. 31). Nesta perspectiva, consideramos que, no processo educacional, esse silêncio por parte dos educadores parece significar e pode ser considerado como uma forma de exclusão do outro justamente porque lhe é negado o direito à voz. Trata-se, na verdade, de uma prática de silenciamento sobre determinadas questões que geram certos incômodos, uma vez que desestabilizam nossos alicerces socioculturais, pois mais importante do que escutar o que é dito sobre os sujeitos, é essencial perceber o não dito, os interditos ou aquilo que é silenciado. Na verdade, tratase de uma prática de silenciamento que "é uma forma de consolidação do preconceito estruturada em bases mais difíceis de serem enfrentadas" (Fontes, 2008, p. 371), pois o currículo, nesta perspectiva, funciona como instrumento de dominação e de exclusão de determinados grupos marginalizados na e pela sociedade.

Se considerarmos ainda que é através do currículo que a instituição escolar revela a sua forma de ver e pensar o mundo, e também uma das formas pelas quais o governo pode exercer o que Foucault denomina por biopoder e governamentalidade, uma vez que demonstra as concepções de mundo, de sociedade, de educação, de ser humano, de comportamentos, e de relações inter e intrapessoais, verificamos que ainda permanece um paradigma tradicional que precisa ser contestado, pois

o currículo da escola está baseado na cultura dominante: ele se expressa na linguagem dominante, ele é transmitido através do código cultural dominante. As crianças das classes dominantes podem facilmente compreender esse código, pois durante toda sua vida elas estiveram imersas, o tempo todo nesse código. [...]. Em contraste, para as crianças e jovens das classes dominadas, esse código é simplesmente indecifrável. Eles não sabem do que se trata. Esse código funciona como uma linguagem estrangeira: é incompreensível. [...]. O resultado é que as crianças e jovens das classes dominantes são bem-sucedidos na escola, o que lhes permite o acesso aos graus superiores do sistema educacional. As crianças e jovens das classes dominadas, em troca, só podem encarar o fracasso, ficando pelo caminho (Silva, 2011, p. 35).

Ainda prevalece o currículo escolar tradicional que não proporciona, de fato, condições plenas para a formação de cidadãos críticos e reflexivos, valorizando as diversidades socioculturais, o que repercute e/ou interfere na formação dos estudantes inseridos na instituição educacional que, na maioria das vezes, apresenta configurações fragmentadas, conteudista, não levando em consideração as possibilidades de leitura das dimensões do todo, o que poderia ser realizado por meio de uma perspectiva inter ou 
transdisciplinar. Precisaríamos, portanto, valorizar as diversidades, evitando "reduzir o multiculturalismo a uma questão de informação" (Silva, 2000, p. 106), incluindo nessa proposta as identidades de gênero e sexuais, uma vez que

[d]iferentes currículos produzem diferentes pessoas, mas naturalmente essas diferenças não são meras diferenças individuais, mas diferenças sociais, ligadas à classe, à raça, ao gênero. Dessa forma, uma história do currículo não deve ser focalizada apenas no currículo em si, mas também no currículo como fator de produção de sujeitos dotados de classe, raça, gênero. Nessa perspectiva, o currículo deve ser visto não apenas como a expressão ou a representação ou o reflexo de interesses sociais determinados, mas também como produzindo identidades e subjetividades sociais determinadas. O currículo não apenas representa, ele faz. É preciso reconhecer que a inclusão ou a exclusão no currículo tem conexões com a inclusão ou exclusão na sociedade (Silva, 2011, p.10).

Ao discutir a problemática que envolve currículo e identidades sociais, Tomaz Tadeu da Silva aponta acertadamente a questão da representação e da produção de identidades e subjetividades no contexto escolar, argumentando que "não existe identidade sexual que não seja já, de alguma forma, discursiva e socialmente construída" (2000, p. 94). Tal prerrogativa nos leva novamente a uma reflexão sobre as práticas discursivas de subjetivação no ambiente escolar e ao processo de disciplinarização dos corpos, uma vez que tanto as nossas identidades quanto os nossos corpos são fabricados, são produtos resultantes de discursos e/ou de mecanismos de poder que tentam controlar e domar as nossas subjetividades. E o discurso é, para Foucault, um mecanismo eficaz de poder.

\section{3) Jovens homossexuais no espaço escolar}

Como dissemos anteriormente, em nossa entrevista semi-estruturada com as/os alunas/os, valemo-nos de questões similares àquelas aplicadas ao corpo docente e técnico, com o objetivo de examinarmos em seus discursos alguns elementos que possam ser contraditórios ou apresentar outra perspectiva em relação ao tratamento das questões de gênero, sexualidade e homofobia no ambiente escolar. A opção pela análise das práticas discursivas de subjetivação se dá devido à premissa de que "a diferença não é uma característica natural: ela é discursivamente produzida” (Silva, 2000, p. 89).

A princípio, sentamo-nos na biblioteca da escola com os alunos membros do grêmio estudantil, um do sexo masculino e outra do feminino; apresentamos-lhes a finalidade da pesquisa e ambos se mostraram receptivos e cientes de sua relevância. Segundo eles, uma das reivindicações apontadas pelos demais integrantes do grupo é justamente incluir palestras, oficinas ou algo parecido abordando a temática da homossexualidade no plano de ação do grêmio. 
Posteriormente, a orientadora educacional encaminhou-nos um aluno que, segundo ela, apresenta "tendências" homossexuais e geralmente é discriminado pelos colegas. Durante a entrevista, o aluno demonstrou muita timidez, mãos suadas e limitou-se a responder objetivamente ao que era perguntado, apesar das instigações de nossa parte. Em seguida, buscamos estabelecer contato com alguns alunos egressos da escola que atualmente "saíram do armário". Um deles se encontra no nível superior e outro concluiu o ensino médio há mais de uma década e, por muitas razões, entre elas a desmotivação causada pela homofobia, não prosseguiu seus estudos. Além desses alunos, também entrevistamos outro aluno homossexual, egresso da escola ainda nas séries iniciais do Ensino Fundamental.

Em relação à primeira e segunda perguntas: "Há algum projeto, interdisciplinar ou não, em desenvolvimento na escola sobre questões relacionadas à sexualidade?" e "Como a escola trabalha com os temas transversais relacionados à sexualidade, ao gênero, à orientação sexual e às doenças sexualmente transmissíveis?”, obtivemos as seguintes respostas:

\begin{abstract}
Aluno I e Aluna II (representantes do grêmio estudantil): "Projeto mesmo não tem, somente alguns professores às vezes durante as aulas que abordam essa questão. Há palestras com professores e outros profissionais da saúde, usam vídeos explicativos, distribuem preservativos etc.".
\end{abstract}

Aluno III: Sim. (Instigamos em saber qual o projeto e a metodologia, mas o aluno limitou-se a esta resposta).

Aluna IV: (matriculada na $1^{\text {a }}$ série do Ensino Médio): "Bom, na escola, desde o início do ano, a única matéria que fala sobre sexualidade é Biologia quando trata da reprodução humana".

Aluno VIII: (egresso há mais de 10 anos): "Não, os professores às vezes paravam o conteúdo da aula para abordar questões de sexualidade".

Aluno IX: (egresso e atual estudante universitário): "Não havia nenhum projeto, os professores abordavam o assunto durante suas aulas relacionando-o com o conteúdo que estavam trabalhando".

Aluno X: (evadido da escola ainda nas séries iniciais do EF): "Não me lembro" (Entrevista semi-estruturada realizada em 07 de dezembro de 2010).

É importante perceber que esses discursos aproximam-se daqueles do corpo docente, ou seja, as questões relacionadas a gênero, sexualidade e identidade na escola ainda permanecem atreladas a uma "visão biológica" do sexo, de modo que não há um projeto pedagógico sistematizado ou planejado, mas somente algumas ações pontuais com o auxílio de parcerias, sobretudo com os profissionais da saúde. A dupla constatação dessa prática pedagógica do trabalho preventivo em relação às doenças sexualmente transmissíveis em parceria com os profissionais da saúde alerta-nos para 
mais uma questão de discriminação e homofobia no ambiente escolar levantada por Louro:

[temos] de prestar atenção se o cuidado com a manutenção da saúde não está sendo feito de modo a rodear o exercício da sexualidade de uma aura de perigo e de doença. Particularmente no caso da Aids é importante notar, ainda, o quanto vem se associando a enfermidade a determinadas práticas sexuais, em especial à prática homossexual, e observar os efeitos dessas associações (2008a, p. 140).

Outro dado interessante, sobretudo nos discursos dos alunos VIII e IX, é o fato de que os professores se valem da mesma metodologia no decorrer dos anos, pois continuam a abordar somente aquilo que diz respeito à reprodução humana e à prevenção de doenças sexualmente transmissíveis ou da gravidez na adolescência, utilizando-se de filmes explicativos. Notamos, portanto, uma prática pedagógica em que se procura adiar insistentemente, através de seus discursos e atos, a atenção sobre a sexualidade humana, fazendo com que, supostamente, prevaleça uma "dessexualização do espaço escolar" (Louro, 2010, p. 20).

O trabalho pedagógico envolvendo estas temáticas ainda gera certo medo, insegurança e restrições, como percebemos nos gestos e semblante de insegurança do aluno III. Este fato leva-nos a concordar que "não só a homossexualidade, sozinha e isolada, que é pouco conhecida e discutida. A sexualidade em todas as suas expressões também" (Viana, 2010, p. 61). A omissão da escola e sua resistência ao diferente é explícita, demonstrando uma necessidade premente de inovação e mudanças significativas na prática pedagógica e em todo o processo educacional.

No decorrer da pesquisa, passamos à terceira pergunta que é justamente sobre as questões de relacionamento interpessoal com colegas homossexuais: "Você tem ou já teve algum/a colega de classe homossexual ou lésbica? Em caso afirmativo, como é/era a convivência com os outros colegas no ambiente escolar?" Eis algumas das respostas obtidas:

Aluno I e Aluna II: "No passado sim, era um homossexual assumido. Com as meninas ele mantinha um bom relacionamento, mas com os meninos havia muito conflito".

Aluno V: "Sim. Dentro da sala ele não era muito criticado, mas fora da sala, ele era chamado por muitos nomes pejorativos".

Aluno X (aluno homossexual evadido): "Sim. Havia muito conflito, ele batia nos coleguinhas e também apanhava muito"

(Entrevista semi-estruturada realizada em 07 de dezembro de 2010).

Revista Escrita

Rua Marquês de São Vicente, 225 Gávea/RJ CEP 22453-900 Brasil 
Nestes discursos, observamos que a violência física e verbal predomina nas relações interpessoais entre os alunos assumidamente homossexuais e aqueles considerados heterossexuais. O convívio harmônico ocorre apenas e quase que exclusivamente com as meninas, talvez por estabelecerem entre si certa confiança ou afinidade, o que não ocorre com o relacionamento com os meninos, que hostilizam, desprezam e agridem verbal ou fisicamente aquele que ousa destoar de um padrão predeterminado de masculinidade e virilidade. Percebemos também que,

[em] nossa cultura, a manifestação de afetividade entre meninos e homens é alvo de uma vigilância muito mais intensa do que entre as meninas e mulheres. De modo geral, as expressões físicas de amizade e de afeto entre homens são controladas, quase impedidas, em muitas situações sociais (Louro, 2010, p. 27).

Esta violência contra os jovens alunos homossexuais, muitas vezes, torna-se uma prática cotidiana nas diversas relações estabelecidas na escola tanto entre os colegas quanto com os professores, que a consideram, em alguns casos, algo perfeitamente normal, enquanto outros sequer veem neste ato uma espécie de agressão.

Este fato demonstra, entre outros aspectos, que um dos caminhos prováveis para uma educação que possa propiciar o respeito e a equidade de gênero no ambiente escolar seja a adoção de uma perspectiva da transdisciplinaridade, pois "eliminar a arrogância, inveja, prepotência e adotar respeito, solidariedade, cooperação é a ideia de base na busca de uma nova espiritualidade, ancorada num sistema de conhecimento transdisciplinar" (D’Ambrósio, 1999, p.152).

A quarta e quinta perguntas foram as seguintes: "Qual o posicionamento dos professores e da coordenação pedagógica diante dos alunos homossexuais que sofrem algum tipo de preconceito ou discriminação na escola?" e se "Há registros de homofobia dentro da escola? Há/houve agressões físicas ou verbais? Em caso afirmativo, como a escola procura sanar estes casos?"

Eis algumas das respostas que obtivemos:

\begin{abstract}
Aluno I e Aluna II: “A direção/coordenação punem os agressores com advertência oral e escrita, também há suspensão das aulas, geralmente buscam o diálogo, envolvendo os pais dos agressores e agredidos. Há registros de agressão verbal apenas, já houve casos em que se envolveu a polícia fora do pátio da escola, o policiamento foi chamado pelo próprio aluno homossexual agredido".
\end{abstract}

Aluno VIII: "Quando eu estudava, lembro-me de uma briga entre uma aluna lésbica e outra heterossexual, ambas rolaram pelo chão e o caso foi encaminhado para coordenação que aplicou advertência escrita às duas. Houve um ano (em outra escola adjacente) que coincidiu de haver quatro alunos homossexuais numa mesma sala de 
aula, a atitude da coordenação foi nos separar imediatamente, transferindo cada um para uma turma diferente" (muitos risos...).

Aluno IX: “Ah, os professores eram muito neutros em relação à questão, mantinham-se à distância... (pausa) e não se manifestavam em relação a isso... já a coordenadora incentivava-me a assumir minha homossexualidade. Houve agressão física e verbal. A escola de certa maneira não enfatizava a questão da agressão verbal, atitudes de advertência ocorriam somente quando ocorria agressão física"

(Entrevista semi-estruturada realizada em 07 de dezembro de 2010).

Nesses discursos, percebemos que a atitude da escola, de modo geral, oscila em aquiescer, omitir ou punir. Nesses depoimentos, observamos que, em diferentes contextos, a escola exerce, veementemente, o caráter punitivo, principalmente quando há agressões físicas, mas, infelizmente, em relação à verbal praticamente não há uma efetiva contrapartida da escola, mesmo porque, neste caso, são muitos os alunos que ferem a imagem do outro por meio de injúrias, o que nos remete à necessidade de uma efetiva política pedagógica no ambiente escolar para a conscientização das diferenças de gênero, sexuais e de identidades. Nesse contexto de coerção e omissão da escola, podemos considerar que, em ambos os casos, a escola torna-se a "principal agente (des)legitimador na produção de significados e se a sua voz se cala frente à homofobia, ela está consentindo esse tipo de situação, tacitamente garantindo a legitimidade dos ataques", de modo que o bullying homofóbico manifesta-se explicitamente, uma vez que essa "violência escolar tem por objetivo atacar pessoas que não se enquadram naquilo que é comumente esperado", sendo "a homofobia [...] institucionalmente aceita" (Roland, 2003, 37-38).

Percebemos ainda nos risos expressos pelo aluno VIII que as consequências de determinadas atitudes pedagógicas dentro da escola podem ferir profundamente a personalidade do indivíduo, a ponto de ele mesmo crer que de fato é um ser "anormal", tornando esses "corpos marcados social, simbólica e materialmente - pelo próprio sujeito e pelos outros" (Louro, 2008b, p. 83), como ocorre com esse informante da pesquisa que se sente completamente desmotivado para prosseguir seus estudos, optando por abandonar a escola. Ainda em relação aos risos de nosso informante, percebemos que "ao rir dos outros homossexuais, um homossexual ri de si mesmo" (Eribon, 2008, p. 94), ou seja, há o apagamento do indivíduo, enquanto ser consciente de sua subjetividade/individualidade e também enquanto ser social, isto é, a atitude de rir ou zombar do próprio grupo ao qual pertence seria uma possível estratégia inconsciente de se dissociar do grupo altamente excluído e oprimido socialmente.

Gostaríamos de ressaltar que em nossa discussão não temos como objetivo apontar a escola e aqueles que nela trabalham única e exclusivamente como responsáveis por esses atos de discriminação e de preconceito, mas defender um posicionamento no qual "a educação plena concilia esses dois aspectos, o individual que leva a atingir a plenitude de sua criatividade - e o social - que leva a integrar-se na 
humanidade como um todo" (D'Ambrósio, 1999, p. 108). Estas são duas dimensões às quais precisamos estar mais atentos no processo de formação de nossos alunos e alunas de modo a garantir a eles/elas o que o referido autor denomina como "cidadania planetária", possível a partir do momento em que haja o "respeito pelas individualidades" no ambiente escolar e também fora dele.

Ainda em relação a este posicionamento da escola, Guacira Louro afirma que não se pode

[a]tribuir à escola nem o poder nem a responsabilidade de explicar as identidades sociais, muito menos de determiná-las de forma definitiva. É preciso reconhecer, contudo, que suas proposições, suas imposições e proibições, fazem sentido, têm efeitos de verdade, constituem parte significativa das histórias das pessoas [...]. Os corpos dos indivíduos devem, pois, apresentar marcas visíveis desse processo, marcas que, ao serem valorizadas por essas sociedades tornam-se referência para todos (2010, p. 21).

Trata-se, pois, de práticas discursivas de subjetivação no ambiente escolar que contribuem, de alguma forma, para a constituição das identidades de gênero e sexuais legitimadas social e culturalmente em nossa sociedade: "[o] que somos, nossas identidades sociais, portanto, são construídas por meio de nossas práticas discursivas com o outro" (Moita Lopes, 2002, p. 32), de modo que defendemos a ideia de que as distintas práticas discursivas marcam e moldam os corpos e as subjetividades dos sujeitos, principalmente daqueles que estão em processo de formação.

Em seguida, passamos ao seguinte questionamento: "Seus professores, em algum momento, trabalharam em sala de aula com as noções de gênero, sexualidade e identidade? Em caso afirmativo, que metodologias, suportes e materiais foram utilizados?"

Eis o recorte que fizemos das respostas obtidas:

\begin{abstract}
Aluno I e Aluna II: "Sim. Os professores trazem textos extraídos de revistas e geralmente há muito debate sobre o assunto. Houve uma época que a rede Globo de televisão exibiu o filme "O segredo de Brokeback Mountain", assistimos em casa e pedimos à professora para comentarmos em sala. Houve também uma boa discussão em sala sobre um filme que assistimos em classe (não lembro o nome) que tinha um garoto que gostava de balé e era criticado por isso".
\end{abstract}

Aluno VIII: "Lembro-me que os professores usavam filmes explicativos, cartazes, simulações do uso do preservativo, porém na maioria dos casos eram as professoras mulheres que trabalhavam o assunto, os professores homens nem falavam nisso".

Aluno IX: "Nunca tive aulas específicas sobre essas questões de identidades, o foco mesmo era na questão do sexo biológico. De vez em quando havia palestras com enfermeiros"

(Entrevista semi-estruturada realizada em 07 de dezembro de 2010). 
Essa questão se relaciona mais diretamente às ações metodológicas adotadas no contexto da sala de aula. Novamente o suporte filme e palestras são utilizados com maior frequência para tratar de questões relacionadas à sexualidade, pois o filme por si só é auto-explicativo e ameniza a intervenção/mediação do professor. Aliás, o trabalho com estas temáticas sempre é atribuído às professoras, o que nos revela a ausência, o silêncio ou até mesmo a dificuldade que os professores do sexo masculino têm para abordarem estes temas em suas práticas pedagógicas, sobretudo por causa da masculinidade e da virilidade que consideram essenciais para aquele que deve ser macho. Além disso, as discussões, quando ocorrem, restringem-se somente ao âmbito biológico, não abordando, de fato, as relações entre gênero, identidade e sexualidade.

Os discursos do aluno I e da aluna II expressam de modo explícito a necessidade de uma discussão em sala de aula sobre o filme assistido em casa: "O segredo de Brokeback Mountain". Isso nos revela que a homossexualidade é um tema que desperta certa curiosidade por grande parte dos alunos e poderia ser abordado de forma ampla e expressiva através deste filme, que mostra, entre outras questões, o relacionamento homoafetivo entre os dois protagonistas e, principalmente, o preconceito e a discriminação que levou um deles à morte. Lúcia Facco, entre outros estudiosos, insiste em apontar a ficção como um instrumento de reflexão sobre algumas problemáticas sociais, de modo que caberia à escola incluir esses temas nas pautas do cotidiano das salas de aula, problematizando essas questões, já que cada vez mais a mídia os explora por meio de debates, de ficção e de entretenimento:

Realmente acredito que a arte, com seu poder criativo e a fascinação que provoca, seja um instrumento privilegiado para a construção de novos pensamentos, que possam sacudir a sociedade estagnada em meio a um mar de preconceitos. Portanto, ela pode e deve ser utilizada por pais e educadores para a formação de seres humanos melhores (Facco, 2009, p. 254).

As questões de sete a onze foram direcionadas, exclusivamente, para os alunos assumidamente homossexuais, pois dizem respeito às práticas de sociabilidade no ambiente escolar. Os discursos destes alunos nos remetem de modo explícito àqueles "corpos marcados" (Louro, 2008b), como é o caso do discurso do aluno egresso da escolacampo, ao ser interpelado sobre as práticas de discriminação e preconceito na instituição escolar:

Ah, o meu relacionamento era muito restrito, eu era muito rejeitado e eu também rejeitava por medo de ser excluído de vez de todo o processo educacional, geralmente nos trabalhos em grupo, os colegas meninos não me aceitavam no grupo e eu me relacionava apenas com as meninas. Os professores sempre me tratavam bem, mas... tipo assim... (pausa) os professores homens privilegiavam as meninas, faziam de conta 
que eu não existia na sala (...). Até mesmo na Universidade hoje ainda me sinto excluído, por exemplo, nenhum colega homem quer fazer trabalho comigo (Entrevista semi-estruturada realizada em 07 de dezembro de 2010 com o aluno IX).

Trata-se, pois, de um indivíduo que, de alguma maneira, expressa em seus gestos, em seus modos de andar, de falar ou de se vestir uma identidade que é estigmatizada. A rejeição é uma forma de violência simbólica que leva à exclusão social e cultural dos homossexuais, alijando-os de uma convivência pacífica em meio àqueles que se consideram heterossexuais. Esta forma de violência simbólica de rejeição e exclusão do outro ocorre em distintos espaços de sociabilidade, indo desde o espaço do colégio até o da universidade, ambos espaços de educação formal que deveriam, em tese, ser laicos e respeitar a diversidade de nossos alunos, pois, enquanto professores, responsáveis em certa medida pela formação daqueles que estão na escola ou na universidade, deveríamos ensinar o respeito em relação ao outro e aos valores socioculturais e históricos constitutivos de sua identidade.

Essas práticas de preconceito e discriminação se estendem por todos os setores sociais e prevalece durante toda a vida do indivíduo, pois por onde ele passe a sociedade o estigmatiza e o rotula, conforme observarmos no discurso de outro aluno egresso da escola em resposta à seguinte pergunta: "Além do ambiente escolar, você sofre/u algum tipo de discriminação ou preconceito? No trabalho? Na rua? Enfim, em diferentes espaços públicos você percebe/u alguma forma de rejeição?"

No trabalho, eu fui já fui explorado com excesso de trabalho e meus patrões diziam claramente que era para eu virar homem, impuseram que eu cortasse meu cabelo para continuar no trabalho. Todos os dias, quando saio na rua, ouço 'chacotas' das pessoas quando eu passo. Certa vez, fui a um balneário público e quando entrei na água, todos os presentes retiraram-se dizendo que não queriam 'pegar doença'. Lembro-me também de uma época em que meu sobrinho pequeno estudava nas séries iniciais do Ensino Fundamental e estava chegando em casa com surra dos coleguinhas que insultavam-no, dizendo-lhe que ele era gay porque era meu parente, tive que intervir no caso, fui à escola, brigamos tanto que o caso envolveu a polícia, com boletim de ocorrência, devido lesões provocadas nas vítimas envolvidas (Entrevista semi-estruturada realizada em 07 de dezembro de 2010 com o aluno VIII).

Neste caso, as práticas de sociabilidade em espaços públicos como, por exemplo, o local de trabalho, também é um dos momentos cruciais para esses indivíduos que se veem marcados, estigmatizados constantemente, levando-os a serem subjugados e até mesmo explorados em virtude de serem gays, de não se adequarem aos padrões de masculinidade e é justamente devido a este "desvio" do normal, do estabelecido, que os outros se sentem no direito de rebaixá-los ou de desprezá-los. Esse discurso revela ainda uma concepção equivocada acerca da homossexualidade quando nosso informante nos diz que em alguns casos já ouviu dizer que é uma espécie de doença contagiosa, que pode ser transmitida até mesmo pelo simples contato, o que leva simplesmente à 
rejeição e ao isolamento destes indivíduos "contaminados", cujos corpos são considerados como "doentes".

Além disso, em outro momento, outro informante em resposta à mesma pergunta afirma: "ah... vários preconceitos eu sofro a cada dia, é só botar a cara para fora (sic) (risos)" (Entrevista semi-estruturada realizada em 07 de dezembro de 2010 com o aluno $\mathrm{X}$ ), o que nos remete a uma afirmação precisa de Guacira Lopes Louro, pois é "como se a homossexualidade fosse 'contagiosa', cria-se uma grande resistência em demonstrar simpatia para com sujeitos homossexuais: a aproximação pode ser interpretada como uma adesão a tal prática ou identidade" (2010, p. 29). Nesse ato discursivo de nosso informante, compreendemos que um dos efeitos da injúria é, conforme afirma Eribon (2008), justamente apagar as singularidades e/ou a subjetividade dos indivíduos.

Agindo dessa maneira, a sociedade pró́be, impõe, aquiesce ou se omite profundamente e, consequentemente, o indivíduo que é alvo de todo esse "mundo de injúrias" torna-se estigmatizado socialmente, relegado a sobreviver de maneira alternativa ou à margem das regras e normas sociais. Este fato

[...] consiste numa atitude de distanciamento, na qual a hostilidade ou o vivido persecutório são substituídos pela desqualificação do sujeito como ser moral [...] significa não vê-lo como agente autônomo [...] um parceiro [...] ou, por fim, como alguém que deve ser respeitado em sua integridade física e moral [...]. No estado de alheamento, o agente da violência não tem consciência da qualidade violenta de seus atos (Costa, 1995, p. 70, grifos do autor).

Distanciamento, desqualificação, hostilidade e violência física e verbal são ações que fazem parte do cotidiano dos sujeitos homossexuais. E perguntamos: e os direitos humanos, segundo os quais todos nós somos iguais e deveríamos ser tratados com isonomia? Ora, o que ocorre é justamente um "alto grau de violação de direitos humanos perpetrado pela homofobia [...]. Ao lesionar uma gama tão ampla de bens jurídicos, a homofobia manifesta-se de violência: física e não física” (Rios, 2009, p. 72).

E a escola também é um expressivo espaço para a socialização entre os diversos estudantes. Em sua reflexão sobre o espaço escolar e a presença dos jovens homossexuais neste ambiente, Guacira Louro afirma que,

[...] sem dúvida, é um dos espaços mais difíceis para que alguém "assuma" sua condição de homossexual ou bissexual. Com a suposição de que só pode haver um tipo de desejo e que esse tipo de desejo - inato a todos - deve ter como alvo um indivíduo do sexo oposto, a escola nega e ignora a homossexualidade (provavelmente nega porque ignora) e, desta forma, oferece muito poucas oportunidades para que adolescentes ou adultos assumam, sem culpa ou vergonha, seus desejos. O lugar do conhecimento mantém-se, com relação à sexualidade, como lugar do desconhecimento e da ignorância (2010, p. 30). 
Em relação a esta dificuldade em se assumir publicamente como homossexual no ambiente escolar e sobre a rejeição ou as práticas de hostilidade e de violência, vejamos alguns recortes de nossos participantes:

$\mathrm{Na}$ escola, fui várias vezes colocado no meio do corredor, sendo empurrado pelo emparedamento de garotos, chorei muito, então corri e fui em casa e chamei meu irmão para ir à escola para ameaçar aqueles meninos (Entrevista semi-estruturada realizada em 07 de dezembro de 2010 com o aluno VIII).

Na escola, eu era batizado como 'o viadinho' (sic), já me espancaram muito, pancadas mesmo (suspiros), tive também um professor homem que era muito preconceituoso comigo, não me aceitava, falava alto comigo e muitas vezes me deixou sem recreio (Entrevista semi-estruturada realizada em 07 de dezembro de 2010 com o aluno X).

De fato, a realidade de jovens homossexuais no ambiente escolar é bastante hostil. Atitudes cotidianas de preconceito e discriminação violam o direito à vida simultânea da diversidade de identidades e expressões da sexualidade, ofendendo explicitamente o pluralismo, que é um dos requisitos fundamentais para a vida democrática.

Salta aos olhos nos discursos desses informantes a presença constante da injúria. Para Didier Eribon, no processo da injúria é

o íntimo que é visado, o mais profundo do ser, o que toda a tradição espiritualista chamou de "alma". E, se a injúria efetivamente recebida provoca um eco tão forte na consciência daquele que a recebe, é porque essa "alma" foi fabricada pela socialização num mundo de injúrias e de inferiorização (2008, p. 86).

No mundo das injúrias as palavras difamatórias, os insultos e a chacota estão presentes no cotidiano desses cidadãos estigmatizados socialmente, tornando sua "alma" altamente sujeitada a uma linguagem que tem como pilar uma representação depreciativa. Em alguns casos, essa representação negativa ocorre desde a tenra idade, levando jovens e crianças de diferentes meios sociais a aprenderem "que há pessoas que podem ser xingadas de "viado" ou de "sapatão", e um dos efeitos mais temíveis e mais eficazes dessa injúria é que ela opera como um ato de censura, como a formulação de um interdito que se endereça a toda a população pelo fato de ditar, garantir e reforçar a norma heterossexual, barrando aquilo que é estigmatizado pela linguagem", de modo que os jovens homossexuais que ousam "sair do armário" passam a viver em um "mundo de injúrias no qual são xingados, real ou potencialmente de "viado nojento" ou de "sapatão" e, por conseguinte, sempre serão, de uma maneira ou de outra, marginalizados ou ostracizados" (Eribon, 2008, p. 83; 147). Esta sujeição privilegia os 
considerados "normais" pela sociedade, enquanto desqualifica e humilha os sujeitos que transgridem o que a sociedade não consegue tolerar e/ou respeitar.

Outro dado importante na discussão sobre a escola como espaço para a equidade de gênero é a situação de humilhação, submissão, rejeição e violência contra os jovens homossexuais, o que gera, muitas vezes, a evasão e o fracasso escolar: "Parei de estudar porque não consegui suportar mais tanto preconceito na escola, lá sequer podia usar minhas roupas femininas, então resolvi desistir de estudar. Ah... (pausa) quem sabe ... talvez um dia eu volte a estudar" (Entrevista semi-estruturada realizada em 07 de dezembro de 2010 com o aluno X).

Este discurso é emblemático de uma violência não somente contra a homossexualidade do indivíduo, mas principalmente por ele se travestir de mulher, ou seja, o aluno homossexual, ao optar publicamente por usar roupas do gênero feminino, rompe agressivamente com os valores enraizados em nosso imaginário sociocultural, como se a vestimenta usada travestisse ou apagasse completamente a dignidade humana:

Aqueles e aquelas que transgridem as fronteiras de gênero ou de sexualidade, que as atravessam ou que, de algum modo, embaralham e confundem os sinais considerados "próprios" de cada um desses territórios são marcados como sujeitos diferentes e desviantes. Tal como atravessadores ilegais de territórios, como migrantes clandestinos, [...] esses sujeitos são tratados como infratores e devem sofrer penalidades (Louro, 2008b, p. 87).

Relacionando essa assertiva de Guacira Louro ao discurso do aluno X, percebemos que a escola não soube/sabe adequar-se a esse "corpo estranho", negando "uma atitude de sofisticação cosmopolita de convivência para a qual nada que é humano the é estranho" (Silva, 2009, p. 98, grifos nossos) e, pedagogicamente, negalhe, ainda, o acesso à educação, tolhendo o seu pleno direito à cidadania, justamente porque a escola ainda não consegue trabalhar pedagogicamente com as rupturas explícitas de certos padrões de masculinidade e de virilidade.

Paradoxalmente, diante da realidade da experiência escolar negativa, vivenciada pelo aluno X, que abandonou a escola ainda nas séries iniciais do Ensino Fundamental, observamos a veiculação de um discurso oficial, por parte do governo, em diversos meios de comunicação de massa, afirmando que o acesso à educação básica, gratuita e laica é, em tese, para todos/as, mas não há, efetivamente, políticas públicas ou ações que garantam este direito de modo igualitário.

\section{4) Considerações finais}


Em todos os momentos de nossa entrevista com esses alunos, observamos semblantes de desilusão e alguns traços de expressão de corpos duramente cingidos ao relatar suas dores, aflições, angústias e medos para sobreviverem em meio às discriminações pelo fato de não sentirem desejos eróticos pelo sexo oposto, uma vez que, de maneira genérica, "a matriz heterossexual exclui aqueles que não se identificam com essas normas, sendo considerados sujeitos e/ou corpos abjetos que estão à margem da sociedade" (Camargo, 2010, p. 75).

Ademais, julgamos importante mencionar que o momento específico das entrevistas com nossos informantes foi marcado por um misto de seriedade e humor característico e peculiar, afinal eles aprenderam a sobreviver em meio às proibições impostas, e "o exibicionismo e a teatralidade estão, com certeza, e estiveram historicamente, entre os gestos mais importantes que permitiram desafiar a hegemonia heteronormativa".

Talvez tenha sido justamente graças a esse humor e irreverência peculiares que estes sujeitos têm sido e "sempre foram objetos de ataques tão virulentos" (Eribon, 2008, p. 132), fato que pode ser comprovado com os altos índices de crimes hediondos contra gays, lésbicas, bissexuais, travestis e transexuais ocorridos com frequência em nosso país e veiculados pela mídia televisiva e impressa.

Esses estudantes que ousaram "sair do armário" e romper com as normas preestabelecidas pagam um considerável preço social por esta ousadia:

[e]sses sujeitos considerados "ousados" escapam àquela via planejada, subvertem as fronteiras constantemente vigiadas dos gêneros e da sexualidade, extraviam-se por outros caminhos que podem ser ásperos ou não. Eles assumem a sua sexualidade, "saem do armário", atravessam as fronteiras, os limites impostos, e escolhem caminhos transversos, onde o ilícito, por vezes, circula. Alguns atravessam logo essa demarcação de espaços, outros permanecem no entre-lugar da fronteira, compreendida como um lugar de relação, região de encontro, de confronto, de cruzamentos, de desejos à deriva $\mathrm{e}$ de medo. Por fim, há aqueles que optam por se manterem dentro dos limites, por medo, por insegurança, não sabemos ao certo os motivos, apenas que são vários (Camargo, 2010, p. 77-78).

Neste sentido, comungamos a ideia de que esses sujeitos "ousados" que rompem as fronteiras são indispensáveis na estrutura sociocultural, uma vez que esses "corpos que não se conformam nunca, completamente, às normas pelas quais sua materialização é imposta" (Butler, 2010, p. 154) "colocam também em xeque o paradigma do gênero binariamente fechado, atribuindo aos sujeitos a possibilidade de "serem" para além daquilo que lhes é esperado" (Inácio, 2010, p. 119), emergindo assim a necessidade premente de repensar essa oposição sociocultural binária heterossexual/homossexual como uma forma para manter tal estrutura. Partindo da premissa de que "a identidade é sempre uma relação: o que eu sou só se define pelo que não sou; a definição da minha 
identidade é sempre dependente da identidade do outro", ou seja, a ratificação ou a definição da heterossexualidade "é inteiramente dependente da definição do seu outro, a homossexualidade" (Silva, 2000, p. 110; 111).

Portanto, deveríamos repensar a interdependência dos seres humanos, a possibilidade de formas alternativas de se viver a sexualidade e conceber a escola como espaço possível para a equidade de gênero e a diversidade sexual sem subjugar ou dela excluir ou silenciar aqueles considerados diferentes. Estes sujeitos não podem ser simplesmente alijados do processo educacional, daí a necessidade de revermos alguns de nossos paradigmas educacionais nas formações iniciais e continuadas de professores de modo a lhes possibilitar um mínimo de conhecimento acerca de questões tão caras ao processo de formação de nossos alunos.

\section{Referências Bibliográficas}

BRASIL. Parâmetros Curriculares Nacionais: temas transversais para o Ensino Fundamental. Brasília/Secretaria de Educação Fundamental: MEC/SEF, 1998.

Plano Nacional de Educação em Direitos Humanos. Brasília: Secretaria Especial dos Direitos Humanos, Ministério da Educação, Ministério da Justiça, UNESCO, 2008.

BORGES, Zulmira N.; MEYER, Dagmar E. Limites e possibilidades de uma ação educativa na redução da vulnerabilidade à violência e à homofobia. In: Ensaio: avaliação e políticas públicas em educação. 2008, janeiro/março, 16(58), 59-76.

BUTLER, Judith. "Corpos que pesam: sobre os limites discursivos do "sexo"”. In: LOURO, Guacira Lopes (Org.). O corpo educado: pedagogias da sexualidade. Belo Horizonte: Autêntica, 2010, p. 151-172.

CAMARGO, Flávio Pereira. Revendo as margens: a (auto)representação de personagens homossexuais em contos de Caio Fernando Abreu. Tese (Doutorado em Literatura) - Universidade de Brasília, Instituto de Letras - Programa de Pós-Graduação em Literatura, 2010.

COSTA, Jurandir F. A face e o verso: estudos sobre o homoerotismo II. São Paulo: Editora Escuta. 1995.

D'AMBRÓSIO, Ubiratan. Educação para uma sociedade em transição. Campinas, SP: Papirus, 1999.

EGYPTO. Antonio Carlos. “Orientação sexual nas escolas públicas de São Paulo”. In: JUNQUEIRA, Rogério Diniz (Org.). Diversidade sexual na educação: 
problematizações sobre a homofobia nas escolas. Brasília: MEC, Secretaria de Educação Continuada, Alfabetização e Diversidade, UNESCO, 2009.

ERIBON, Didier. Reflexões sobre a questão gay. Rio de Janeiro: Companhia de Freud, 2008.

FACCO, Lúcia. Era uma vez um casal diferente: a temática homossexual na educação literária infanto-juvenil. São Paulo: Summus, 2009.

FONTES, Malu. "Ilustrações do silêncio e da negação: a ausência de imagens da diversidade sexual em livros didáticos”. In: Psicologia Política, 8(16), 363-378, 2008.

FOUCAULT, Michel. Microfísica do poder. Rio de Janeiro: Graal, 1993.

Ética, sexualidade e política. Rio de Janeiro: Forense Universitária, 2006.

Vigiar e punir: o nascimento da prisão. Petrópolis: Vozes, 2009.

HEILBORN, Maria Luiza. Sexualidade no plural: o direito à diferença. Disponível em http://www.clam.org.br/publique/media/sexualidade no plural.pdf. Acesso em $17 \mathrm{de}$ dezembro de 2010.

INÁCIO, Emerson da Cruz. "Para uma estética pederasta". In: COSTA, Horácio... [et al] (Orgs.). Retratos do Brasil homossexual: fronteiras, subjetividades e desejos. São Paulo: Editora da Universidade de São Paulo; Imprensa Oficial do Estado, 2010, p. 111124 .

JUNQUEIRA, Rogério Diniz. "Homofobia: limites e possibilidades de um conceito em meio a disputas". In: Bagoas. Revista de Estudos gays. Universidade Federal do Rio Grande do Norte, Centro de Ciências Humanas, Letras e Artes. Natal: EDUFRN, 2007, vol. 01, n. 01, jul./dez. 2007, p. 01-22.

LOURO, Guacira Lopes. Currículo, género e sexualidade. Porto: Porto Editora, 2000.

. (Org.). O corpo educado: pedagogias da sexualidade. Belo Horizonte: Autêntica, 2007.

. Gênero, sexualidade e educação: uma perspectiva pós-estruturalista. Petropólis, Rio de Janeiro: Vozes, 2008a.

Um corpo estranho: ensaios sobre sexualidade e teoria queer. Belo Horizonte: Autêntica, 2008b.

"Pedagogias da sexualidade". In: (Org.). O corpo educado: pedagogias da sexualidade. Belo Horizonte: Autêntica, 2010, p. 07-34.

MOITA LOPES, Luiz Paulo da. Identidades fragmentadas: a construção discursiva de raça, gênero e sexualidade em sala de aula. Campinas: Mercado de Letras, 2002. 
- "Gêneros e sexualidades nas práticas discursivas contemporâneas: desafios em tempos queer". In: SILVA, Antonio de Pádua Dias da (Org.). Identidades de Gênero e práticas discursivas. Campina Grande: EDUEP, 2008.

PRADO, Marco Aurélio. MACHADO, Frederico Viana. Preconceitos contra homossexualidades: a hierarquia da invisibilidade. São Paulo: Cortez, 2008.

ROLAND, Beatriz. "A adolescência no contexto escolar: uma história de vida". In: MOITA LOPES, Luiz Paulo da (Org.). Discursos de identidades: discurso como espaço de construção de gênero, sexualidade, raça, idade e profissão na escola e na família. Campinas: Mercado de Letras, 2003, p. 113-134.

SANTOMÉ, Jurgo Torres. "As culturas negadas e silenciadas no currículo". In: SILVA, Tomaz Tadeu da (Org.). Alienígenas na sala de aula. Petrópolis: Vozes, 2011.

SEFFNER, Fernando. "Equívocos e armadilhas na articulação entre diversidade sexual e políticas de inclusão Escolar". In: JUNQUEIRA, Rogério Diniz (Org.). Diversidade sexual na educação: problematizações sobre a homofobia nas escolas. Brasília: MEC/Secretaria de Educação Continuada, Alfabetização e Diversidade, UNESCO, 2009.

SILVA, Tomaz Tadeu da. Teorias do Currículo: uma introdução crítica. Porto: Porto Editora Ltda, 2000.

"A produção social da identidade e da diferença". In: (Org.). Identidade

e diferença: a perspectiva dos estudos culturais. Petrópolis: Vozes, 2009, p. 73-102.

"Currículo e identidade social: territórios contestados". In: (Org.). Alienígenas na sala de aula. Petrópolis: Vozes, 2011.

VIANA, Fabricio. O armário: vida e pensamento do desejo proibido. Blumenau: Ed. do Autor, 2010. 